\title{
Does the shrub layer act as an intermediary? Effects on abundance of insects and abundances of particular insect orders caught flying in the canopies of deciduous forests in Central Germany
}

\author{
Stephanie Stiegel, Anna KORfHAGE and Jasmin MANTILLA-CONTRERAS \\ University of Hildesheim - Biology and Chemistry, Universitätsplatz 1, Hildesheim 31141, Germany; \\ e-mails: stiegel@uni-hildesheim.de, anna.korfhage@web.de, mantilla@uni-hildesheim.de
}

Key words. Insects, Coleoptera, Diptera, Hemiptera, Hymenoptera, Lepidoptera, Neuroptera, Psocoptera, Thysanoptera, Fagus sylvatica, forest, phytodiversity, plant cover, air temperature, relative air humidity, plant species richness, Germany

\begin{abstract}
Scientists and society are increasingly becoming aware of loss of insect biodiversity and biomass. The level of biodiversity determines the efficiency of ecological communities to capture essential resources, produce biomass, decompose and recycle nutrients. Relationships between plant and insect diversity can be modified by changes in insect abundance. This study determined the associations between microclimate and diversity of forest plants on overall insect abundance and abundances of different insect orders in the canopy of temperate deciduous forests dominated by Fagus sylvatica L. (European beech; Fagaceae) in Central Germany. Following model selection, a linear mixed model was used to analyse the associations between abiotic factors (air temperature and relative humidity) as well as biotic factors (species richness and cover for the ground, shrub and tree layer) and insect abundance and abundances of insect orders. Within similar strength of evidence, best models were chosen as those with a single explanatory parameter. Significant associations were recorded between abundances of Lepidoptera and Neuroptera and relative air humidity, insect abundance and species richness in the shrub layer, and between abundances of Diptera and Psocoptera and percentage cover of shrubs. Trends in associations were detected between the abundance of Hemiptera and species richness recorded in the shrub layer, and between the abundance of Thysanoptera and the species richness in the ground layer. No significant associations with single explanatory parameters were recorded for the abundances of Coleoptera and Hymenoptera. Phytodiversity, especially that in the shrub layer, were more often associated with the abundances of insect orders than microclimatic factors. The potential importance of the association between shrub layer parameters and the abundance of insects might be based on the shrub layer combining the associations with the ground layer (bottom-up processes) and canopy layer (environmental conditions). In addition, associations between phytodiversity and abundance of insects seem to vary most for Coleoptera and Hymenoptera in which there are markedly different functional groups.
\end{abstract}

\section{INTRODUCTION}

Biodiversity is currently an important subject for research and nature conservation mainly motivated by reports of the extinction of many species. Unfortunately, the global decline in biodiversity (e.g. Pimm \& Raven, 2000; Singh, 2002), biomass of arthropods and their abundance (Hallmann et al., 2017; Vogel, 2017; Leather, 2018) is becoming increasingly evident. The loss in biodiversity results in a reduction in the efficiency of ecological communities to produce essential resources, biomass, decompose and recycle nutrients (Cardinale et al., 2012) as is reported for forests (Piotto, 2008; Zhang et al., 2012). There is evidence of an important connection between biodiversity and ecosystem functioning. Therefore, discussions about the role of biodiversity in the stability of ecosystems are frequent and ongoing (McCann, 2000) and determinants of biodiversity becomes an increasingly important field of study in ecology (Kelly \& Southwood, 1999).
Several abiotic and biotic factors affect the diversity and abundance of insects (reviewed by Ulyshen, 2011). Phytodiversity, i.e. the diversity of vascular plants, is supposed to be an important factor for insect diversity in forest ecosystems (Erwin, 1982). In food chains, plants as primary producers are the basic resource for other trophic levels. In forest habitats, tree diversity is positively associated with the overall richness of species of insects (Vehviläinen et al., 2007). Models predict that the greater the number of resources (e.g. phytodiversity) the greater the number of species (Tilman, 1986; Rosenzweig, 1995). This relationship may also hold for the abundance of species of insects as well as their diversity. That is, a greater number of resources (number of plant species or plant abundance/biomass) will support a greater number of individuals of insects. For a species of insect, its abundance determines its population density and stability. Their abundance is dependent on various factors such as environmental favourability, food 
availability and shelter (Berryman, 1986). Higher population densities can be seen as either positive in terms of cooperation between individuals for mating, defence, or attack, or negative in terms of concurrence with resources, leading to population cycles. Therefore, insect abundance plays a role in population stability and loss in the richness of species. According to Schuldt et al. (2019), relationships between plant and insect diversity can be modified by changes in the overall abundance of insects because the significant associations between phytodiversity and species richness of arthropods are often indirect via effects on arthropod abundances.

In regard to abiotic factors, correlations between microclimate and insect diversity or abundance are reported in numerous studies (e.g. Logan et al., 2003; Meineke et al., 2013; Mech et al., 2018). On the one hand, temperature has a positive influence on the growth, development, activity and distribution of insects (Simonet et al., 1981; Wiktelius, 1981; Strathdee et al., 1993; Whittaker \& Tribe, 1998; Levesque et al., 2002). On the other hand, limited and inconsistent results are reported for the direct effects of humidity (Chiarelli et al., 2011). In addition, different species of carabids distinctly differ in terms of their preferred biotic and abiotic factors (Antvogel \& Bonn, 2001). Therefore, there is a need to investigate the effects for at least subgroups because they probably vary for orders and even species of insects.

Globally the greatest abundance and diversity of insects is in the canopies of forest ecosystems (Erwin, 1982; Stork, 1988; Novotny \& Basset, 2005). In comparison to tropical forests, there is little research on insects in the canopies of temperate forests, but has been increasing in Europe recently (e.g. Floren \& Schmidl, 2008; Sobek et al., 2009c; Bouget et al., 2011; Normann et al., 2016). For instance, the importance of the species of tree for the patterns in species richness and abundance of beetles in the canopy of a temperate forest has been demonstrated (Gering \& Crist, 2000). Fagus sylvatica L. (European beech; Fagaceae) is the dominant deciduous tree in German forests (BMEL, 2016). Therefore, its contribution to insect diversity and abundance should be the principal focus of research along with the range of abiotic and biotic factors that determine insect diversity and abundance.

This study investigates the effect of microclimate and phytodiversity on overall abundance and abundances of different orders of flying insects in temperate deciduous forests in Central Germany. Canopies of $F$. sylvatica were surveyed at 20 sites with northern and southern exposures in ten different forest stands. The aim is to determine differences in microclimate and phytodiversity and their associations with total insect abundance and abundances of particular orders of flying insects. The following hypotheses are tested: (1) insect abundance and abundances of insect orders increase with temperature, (2) insect abundance and abundances of insect orders are positively associated with phytodiversity and (3) the determining factors vary for different insect orders.

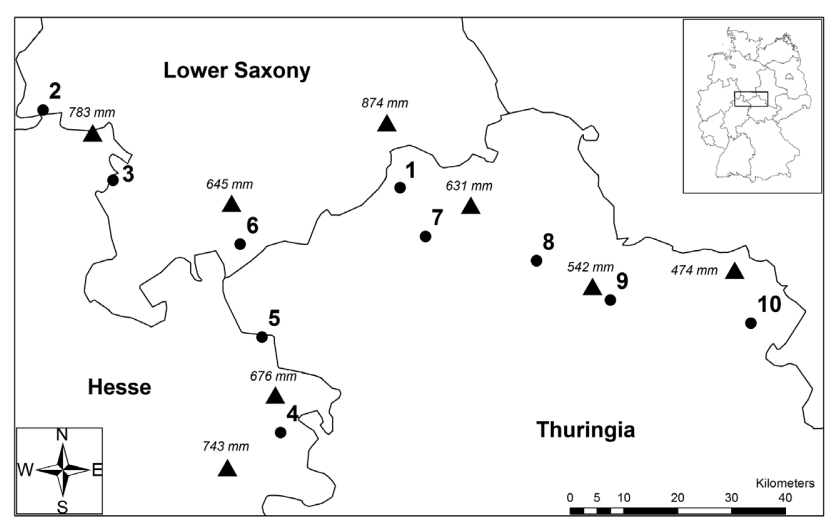

Fig. 1. Map showing the locations of the ten forest sites (circles) studied in Thuringia, Lower Saxony and Hesse. Weather stations (triangles) with mean annual precipitation (italic values) recorded for the period 1961-90 (German Weather Service). Forest sites: 1 - Winkelberg; 2 - Tiefentals Ebene; 3 - Klingenberg/Vaaker Berg; 4 - Schieferstein; 5 - Heiligenberg; 6 - Bocksbühl; 7 - Hubenberg; 8 - Feuerkuppe; 9 - Heidelberg; 10 - Eichleite. Reprinted from BKG under a CC BY license, with permission from Bundesamt für Kartographie und Geodäsie, original copyright GeoBasis-DE/BKG 2015 (data changed).

\section{MATERIAL AND METHODS}

\section{Study area}

The area studied is located in Central Germany within the federal states of Thuringia, Lower Saxony and Hesse. Along a $140 \mathrm{~km}$ east-west transect, ten sites were selected in forest stands dominated by several deciduous species of trees (Fig. 1). These sites were dominated by F. sylvatica, the most common deciduous tree in German forests. In addition, Acer pseudoplatanus L. (sycamore maple; Sapindaceae) and Carpinus betulus L. (hornbeam; Betulaceae) occurred frequently in the understorey. The criteria used in selecting forest stands were (i) a closed canopy, (ii) absence of coniferous trees and (iii) stem circumference of mature beech trees $>1 \mathrm{~m}$. The altitudes of the sites sampled ranged from 140 to $444 \mathrm{~m}$ a.s.l. In each forest stand two sites were selected, one facing north and the other facing south $(\mathrm{n}=$ 20). According to the German Weather Service (reference period: 1961-1990), mean annual precipitation increased along the transect from east to west, ranging from $474 \mathrm{~mm}$ (Artern, Thuringia) to $874 \mathrm{~mm}$ (Herzberg, Lower Saxony). Mean annual temperatures were similar in the different forest stands in the area studied and increased from about $8^{\circ} \mathrm{C}$ to $9^{\circ} \mathrm{C}$ at the beginning of the $21^{\text {st }}$ century (German Weather Service, reference period: 1961-1990 and 1981-2010). The geological substrate at the forest sites was lower Trias sandstone, except for upper Trias sandstone at one site (Bocksbühl) and middle Triassic limestone at two sites (Feuerkuppe and Heidelberg).

\section{Data collection}

The abiotic conditions were air temperature and relative air humidity, which were measured hourly using data loggers (iButton, Model DS1923, Maxim Integrated, San Jose, CA, USA) from July to August 2012. At each site, a data logger was installed in the lower canopy (average height: $18 \mathrm{~m}$ ) of a mature $F$. sylvatica tree. Average values for the measured period for each site were used in the statistical analyses.

The phytodiversity at each site was assessed by surveying the vegetation. Species of angiosperms were recorded in the ground $(0-2 \mathrm{~m})$, shrub $(2-6 \mathrm{~m})$ and tree layers $(>6 \mathrm{~m})$. In a plot of $10 \times$ $10 \mathrm{~m}$ square, abundances of the species in each layer were esti- 


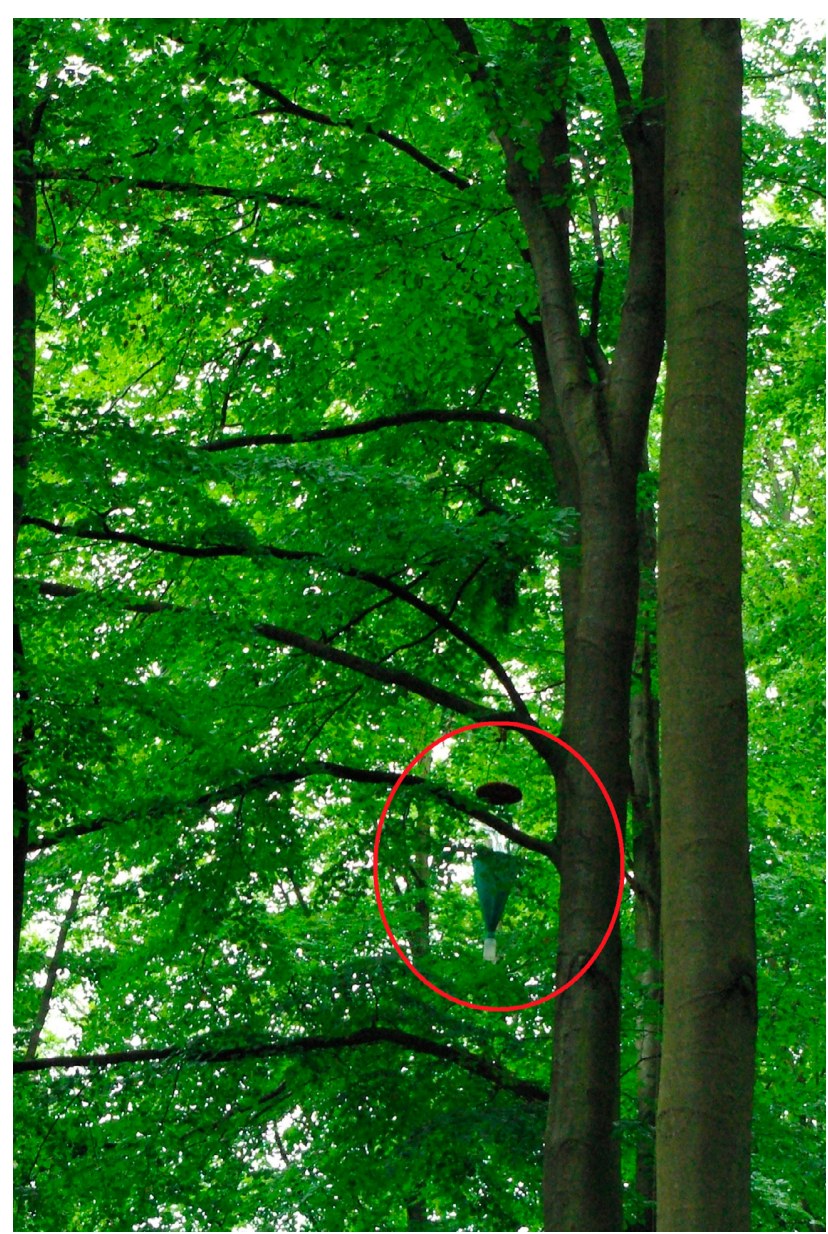

Fig. 2. Window trap (in red circle) installed in the lower canopy (average height: $18 \mathrm{~m}$ ) of Fagus sylvatica for capturing flying insects.

mated using the Londo scale (Londo, 1976) and used as a representation of the vegetation at each of the forest sites. In addition, the ground, shrub and tree cover were estimated visually (plant cover scale in percent). The phytodiversity in each layer was recorded in terms of the number of species of plants per plot (species richness). All three forest layers were included in the analysis because the ground and shrub layer might be important in terms of providing shelter or food for flying insects and so influence their abundances.

Insect abundance and abundances of insect orders in all the forest stands were assessed using window traps that catch flying insects (Fig. 2). At each of the 20 sites sampled three window traps were located in the lower canopy of three randomly chosen mature beech trees ( F. sylvatica) in each forest stand (trees: $\mathrm{n}=60$ ). The average height of window traps above the ground was $18 \mathrm{~m}$. Flying insects intercepted by the traps fell into a saturated saline solution containing a drop of detergent in one-litre-sized containers. The sampling started in June 2012 and ended at the beginning of August 2012. Each window trap was active for about three weeks and the liquid was collected and refreshed on three occasions. Insects caught by the traps were placed in tubes containing $70 \%$ ethanol for storage until analysed. Storms destroyed the catches of some window traps, which resulted in a total number of 167 samples. In the laboratory, captured insects were identified to the level of the order to which they belonged. Orders that do not include flying insects and/or were not present at all sites were not included in the analyses (Collembola, Dermaptera, Ensifera, Ephemeroptera and Mecoptera). Insect abundance and abundance of the insect orders Coleoptera, Diptera, Hemiptera,
Hymenoptera, Lepidoptera, Neuroptera, Psocoptera and Thysanoptera were calculated as the average catch per window trap for each site sampled.

\section{Data analyses}

Statistical analyses were done using $\mathrm{R}$ version 3.4.1 (R Development Core Team, 2017). Statistical distributions of the data for microclimate, vegetation, insect abundance and abundances of insect orders were assessed using the Shapiro-Wilk test. Associations between microclimate (air temperature and relative humidity) and vegetation (species richness and cover of the ground, shrub and tree layers) and insect abundance and abundances of insect orders were determined using selected linear mixed models (LMM). Calculations were done using the R libraries lme4 to determine suitable LMMs and MuMIn to select the most suitable model (Bartoń, 2016; Bates et al., 2017). Abundance values for insects, Diptera, Hymenoptera and Neuroptera were log transformed and those for Lepidoptera squared to reduce the skewness of their distribution. Whether the explanatory variables were correlated with one another was determined using the R libraries ggplot 2 and GGally. The ggpairs function indicates pairs of plots including the correlation coefficients (Fig. S1). There was a strong correlation (correlation coefficient $>0.6$ ) between species richness and cover of ground layer. Therefore, the cover of ground layer was excluded from the final model that included all explanatory variables without strong correlations. For insect abundance and abundances of insect orders, comparisons were made using the final model. All models included the forest site as a random effect. The best models were selected based on the Bayesian Information Criterion (BIC). The lowest BIC value indicated either fewer explanatory variables, better fit, or both. The strength of evidence for different models was similar based on using $\triangle \mathrm{BIC}=0-2$ (Kass \& Raftery, 1995). The final model and model comparisons were done using the following $\mathrm{R}$ codes, respectively:

fullmod $<-\operatorname{lmer}$ (response variable $\sim$ temperature + humidity + species richness of ground layer + species richness of shrub layer + species richness of tree layer + cover of shrub layer + cover of tree layer $+(1 \mid$ site $)$, REML $=$ FALSE $)$

$\bmod <-$ dredge(update(fullmod), rank = "BIC")

Associations between explanatory variables and overall insect abundance and abundances of insect orders were calculated. Models with a single parameter in the range of $\triangle \mathrm{BIC}=0-2$ were selected for plotting. Linear regressions are graphically presented for significant relationships along with trends between explanatory and response variables, based on highest $F$-values and significance levels.

\section{RESULTS}

Overall, the species composition of plants and insect orders differed between the sites sampled. Eight different species of trees were recorded in the tree and shrub layer, while there were 66 species of plants in the ground layer at all the sites sampled. Fagus sylvatica was present at all the sites sampled and in all forest layers. Insect catches using window traps totalled 17,218 individuals belonging to 13 different orders of insects (with a range of 10-12 orders per site sampled): Coleoptera, Collembola, Dermaptera, Diptera, Ensifera, Ephemeroptera, Hemiptera, Hymenoptera, Lepidoptera, Mecoptera, Neuroptera, Psocoptera and Thysanoptera. Most of the insect caught were Diptera $(59 \%)$, followed by Coleoptera $(17 \%)$, with the other or- 
Table 1. The phytodiversity (represented by species richness in the ground, shrub, and tree layer) and insect abundance (represented by the mean number of individuals per window trap) of all sample sites.

\begin{tabular}{|c|c|c|c|c|c|}
\hline \multirow[b]{2}{*}{ Site $^{1}$} & \multirow[b]{2}{*}{ Exposition } & \multicolumn{3}{|c|}{ Plant species richness } & \multirow{2}{*}{$\begin{array}{c}\text { Insect } \\
\text { abundance }{ }^{2} \\
\text { individuals / trap }\end{array}$} \\
\hline & & $\begin{array}{c}\text { Ground } \\
\text { layer }\end{array}$ & $\begin{array}{l}\text { Shrub } \\
\text { layer }\end{array}$ & $\begin{array}{l}\text { Tree } \\
\text { layer }\end{array}$ & \\
\hline \multirow{2}{*}{ WB } & north & 19 & 3 & 3 & $117(7)$ \\
\hline & south & 6 & 3 & 2 & $80(9)$ \\
\hline \multirow{2}{*}{ TE } & north & 7 & 1 & 1 & $92(8)$ \\
\hline & south & 7 & 1 & 2 & $73(6)$ \\
\hline \multirow{2}{*}{ KBVB } & north & 5 & 1 & 3 & $91(9)$ \\
\hline & south & 3 & 2 & 3 & $43(9)$ \\
\hline \multirow{2}{*}{ SS } & north & 6 & 1 & 3 & $101(9)$ \\
\hline & south & 14 & 1 & 5 & $72(9)$ \\
\hline \multirow{2}{*}{ HGB } & north & 22 & 1 & 1 & $56(9)$ \\
\hline & south & 13 & 3 & 2 & $89(9)$ \\
\hline \multirow{2}{*}{ BB } & north & 12 & 4 & 1 & $96(9)$ \\
\hline & south & 9 & 4 & 1 & $171(8)$ \\
\hline \multirow{2}{*}{$\mathrm{HB}$} & north & 21 & 2 & 1 & 107 (8) \\
\hline & south & 11 & 2 & 3 & $124(9)$ \\
\hline \multirow{2}{*}{ FK } & north & 8 & 4 & 1 & $136(9)$ \\
\hline & south & 18 & 3 & 1 & $54(6)$ \\
\hline \multirow{2}{*}{ HDB } & north & 26 & 3 & 1 & $58(9)$ \\
\hline & south & 11 & 1 & 4 & $84(9)$ \\
\hline \multirow{2}{*}{ EL } & north & 15 & 4 & 3 & 264 (8) \\
\hline & south & 4 & 2 & 2 & $122(8)$ \\
\hline
\end{tabular}

${ }^{1}$ Abbreviations: WB - Winkelberg; TE - Tiefentals Ebene; KBVB - Klingenberg/Vaaker Berg; SS - Schieferstein; HGB - Heiligenberg; BB - Bocksbühl; HB - Hubenberg; FK - Feuerkuppe; HDB - Heidelberg; EL - Eichleite. ${ }^{2}$ The number of traps per sample site is given in brackets. Insects are represented by individual numbers of the following orders: Coleoptera, Diptera, Hemiptera, Hymenoptera, Lepidoptera, Neuroptera, Psocoptera and Thysanoptera.

ders (Hemiptera, Hymenoptera, Lepidoptera, Neuroptera, Psocoptera and Thysanoptera) each less than $8 \%$. The species richness of plants and insect abundance varied between and within the sites sampled (Table 1). Plant species richness of ground, shrub and tree layer ranged from 3-26, $1-4$ and $1-5$, respectively. Insect abundances ranged from 43-264 individuals per window trap per site sampled.

The LMM indicates that the explanatory variables for insect abundance differ from those for and abundances of insect orders (Table S1). Other models of similar robustness $(\triangle \mathrm{BIC}=0-2)$, indicate significant and non-significant single explanatory variables associated with abundance of insects and abundances of insect orders (Table 2). Significant effects of single explanatory variables were indicated for abundance of insects (species richness recorded in shrub layer), dipteran abundance (cover of shrub layer), lepidopteran abundance (relative air humidity), neuropteran abundance (relative air humidity) and psocopteran abundance (cover of shrub layer). Trends were found for the explanatory variable associated with hemipteran abundance (species richness recorded in the shrub layer) and thysanopteran abundance (species richness of ground layer). Associations with coleopteran and hymenopteran abundances (relative air humidity and species richness of shrub layer) were not significant.

Generally, neuropteran and lepidopteran abundances are significantly associated with relative air humidity (Fig. 3). The associations with plant species richness differed depending on the forest layer. While the overall insect and hemipteran abundances are positively and significantly associated with the species richness of the shrub layer (Fig. $4 \mathrm{a}, \mathrm{b})$, thysanopteran abundance decreased with increase in the species richness of the ground layer (Fig. 4c). In addition, dipteran and psocopteran abundances are positively and significantly associated with increase in the cover of the shrub layer (Fig. 5).

\section{DISCUSSION}

\section{Abundance patterns of flying insects}

Overall, phytodiversity is more often associated with the abundances of insect orders than microclimatic factors. Despite the positive associations between temperature, growth, development, activity and distribution of insects, none were detected between insect abundance and temperature contrary to our first hypothesis. However, lepidopteran and neuropteran abundances are associated with relative air humidity and it is known that a low relative humidity adversely affects the development of some species of Neuroptera (Tauber \& Tauber, 1983). This could have resulted in the decrease in neuropteran abundance associated with the increase in relative air humidity recorded in this study. The same was recorded for lepidopteran abundance, which is in accordance with the results of Jonason et al. (2014). Increase in air humidity could also be associated with high rainfall, which potentially has a negative effect on the activity of Lepidoptera. Indeed, the weather in June and July in 2012 was more humid due to high rainfall compared to the average values recorded by the German Weather Ser-

Table 2. Effects of abiotic conditions and vegetation parameters on the insect abundance and insect order abundances (linear regressions: $\mathrm{df}($ numerator $)=1 ; \mathrm{df}($ denominator $)=18$ ). Calculations are based on models compared by the Bayesian Information Criterion with similar strength of evidence for $\triangle \mathrm{BIC}=0-2$ (Table S1). The preference was set on models containing single explanatory variables. Underlines indicate parameters with highest F-values and significances for the response variables.

\begin{tabular}{|c|c|c|c|c|c|c|c|c|c|}
\hline \multirow{2}{*}{ Parameters $^{1}$} & \multicolumn{9}{|c|}{$F$-values $^{2}$} \\
\hline & Insects & Coleoptera & Diptera & Hemiptera & Hymenoptera & Lepidoptera & Neuroptera & Psocoptera & Thysanoptera $^{3}$ \\
\hline Temp & & 0.02 & & & & & & 1.16 & \\
\hline Humid & & 2.00 & & & 1.90 & ${\underline{5.77^{*}}}^{*}$ & $11.04^{\star *}$ & & \\
\hline SRG & & & & & & & & & $3.32^{t}$ \\
\hline SRS & $4.54^{*}$ & & & $\underline{3.96}^{t}$ & 1.95 & & & & \\
\hline CS & $4.23^{t}$ & & $\underline{6.76}^{*}$ & 2.80 & & & & $\underline{5.08}^{*}$ & \\
\hline
\end{tabular}

${ }_{1}^{1}$ Abbreviations: Temp - air temperature; Humid - relative humidity; SRG - species richness recorded in ground layer; SRS - species richness recorded in shrub layer; CS - cover of shrub layer. ${ }^{2}$ Significance codes: ${ }^{\mathrm{t}}-p<0.1 ;{ }^{*}-p<0.05 ;{ }^{* *}-p<0.01{ }^{3}$ Tested model for thysanopteran abundance had a positive strength of evidence $(\triangle \mathrm{BIC}=2-6)$ compared to the model with the lowest $\mathrm{BIC}$ value. 

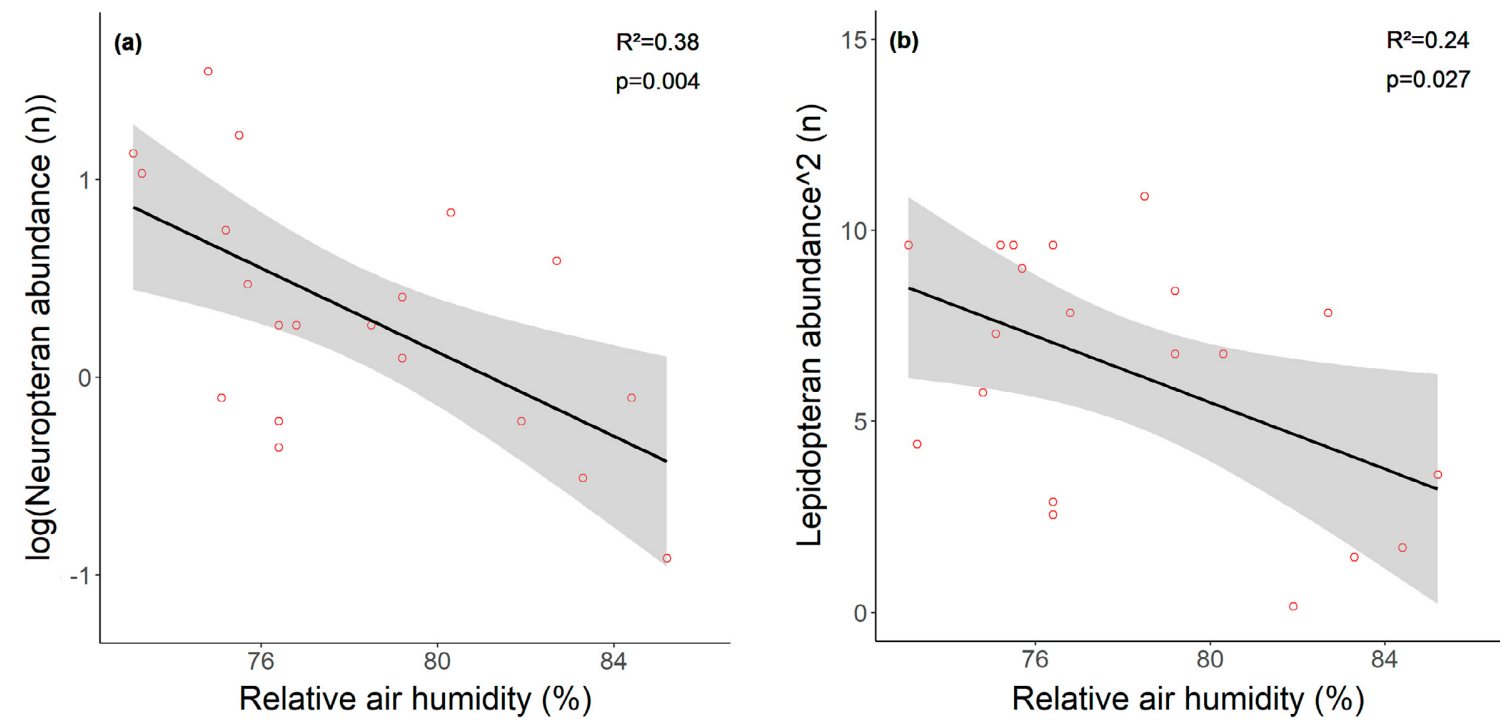

Fig. 3. Significant relationships between the response variable and relative air humidity $(n=20 ; C l=95 \%)$ based on linear regressions (Table 2): (a) abundance of Neuroptera and (b) abundance of Lepidoptera.
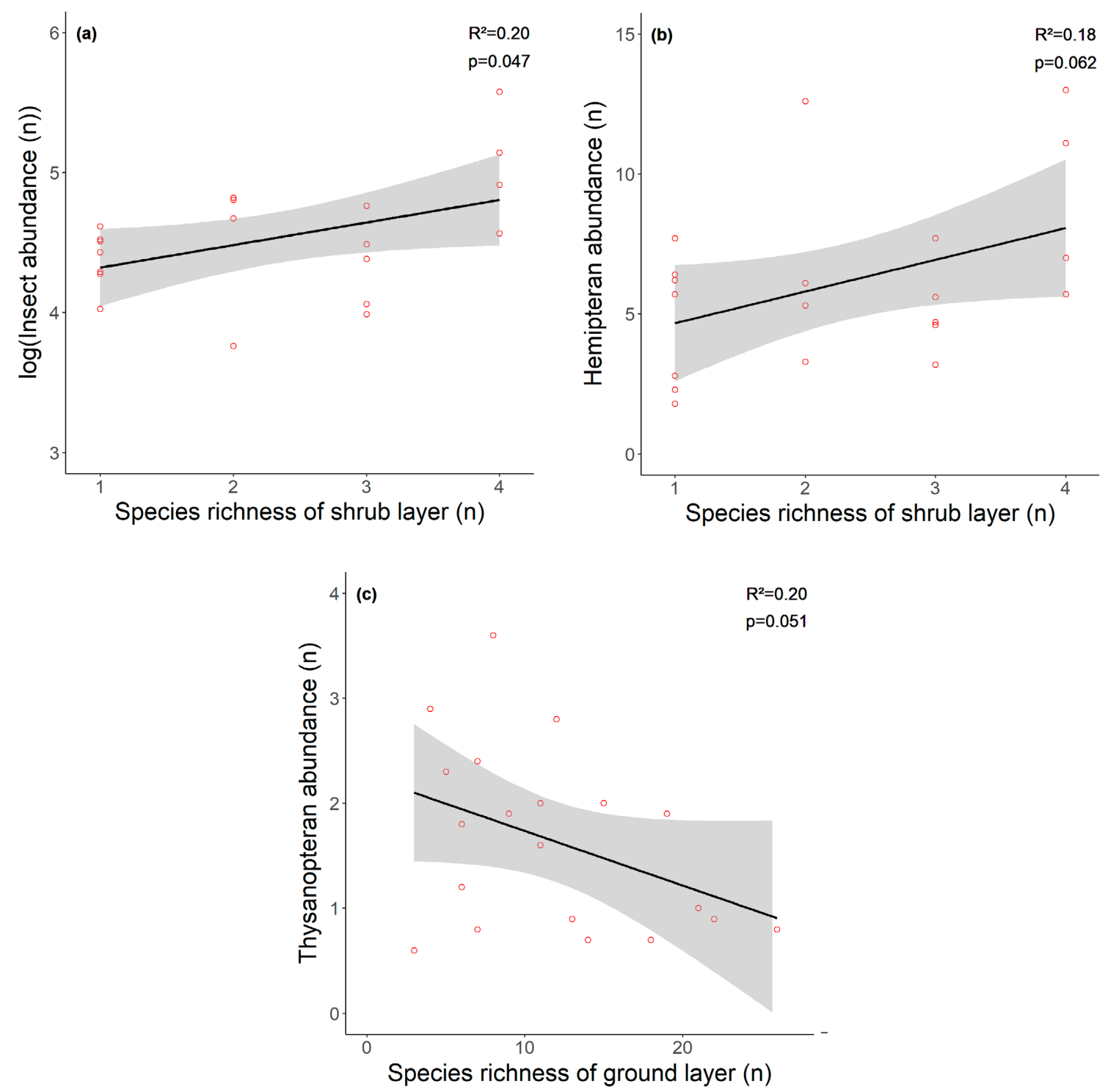

Fig. 4. Significant and trend relationshipss between response variables and plant species richness $(n=20 ; \mathrm{Cl}=95 \%)$ based on linear regressions (Table 2): (a) abundance of insects and species richness of the shrub layer, (b) abundance of Hemiptera and species richness of the shrub layer and (c) abundance of Thysanoptera and species richness of the ground layer. 

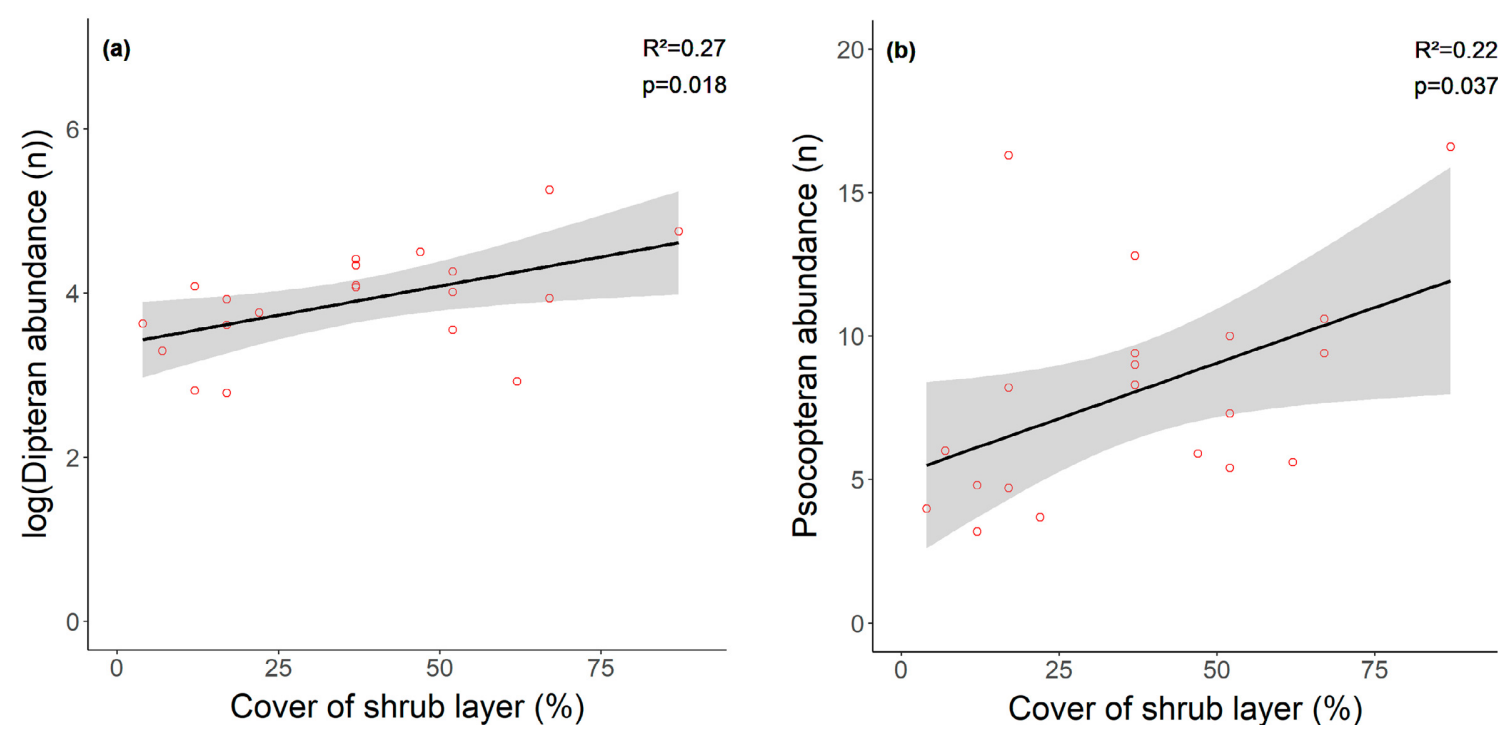

Fig. 5. Significant relationships between the response variable and cover of the shrub layer $(n=20 ; C l=95 \%)$ based on linear regressions (Table 2): (a) abundance of Diptera and (b) abundance of Psocoptera.

vice. Generally, temperature is an important determinant of flight activity in Lepidoptera as light traps catch more moths during warm than cold nights during their most active period (McGeachie, 1989; Yela \& Holyoak, 1997; Jonason et al., 2014), which is because of the positive association between the activity of poikilothermic species and air temperature (Holyoak et al., 1997).

Abundances of Lepidoptera and Neuroptera are also affected by phytodiversity. Although the abundance of Lepidoptera is not associated with plant abundance there is a direct link between their abundance and the species diversity of plants (Root et al., 2017). According to the nichepartitioning hypothesis, a high phytodiversity provides a greater diversity of niches (Chesson, 2000), which could support the existence of more species of Lepidoptera. Tree species diversity also increases the diversity and abundance of dominant neuropteran species, which indicates different levels of association with host trees (Gruppe \& Sobek, 2011). According to the enemies hypothesis, habitats rich in species of plants offer more alternative prey, additional food and shelter for predators and parasitoids (Root, 1973). Therefore, it is hypothesized that the diversity of predators belonging to different taxa increases with increase in phytodiversity via direct (more structural and floral resources) and indirect (greater abundance and diversity of prey) pathways (Hunter \& Price, 1992; Siemann et al., 1998). However, direct positive effects of phytodiversity decline with increase in trophic level and the degree of omnivory (Scherber et al., 2010). Relative abundances of predators and parasitoids are higher in plant species-rich plots (Sobek et al., 2009b). However, phytodiversity effects on species richness at higher trophic-levels are often mediated by alterations in the abundance of the consumers (Schuldt et al., 2019). Many species of Lepidoptera are highly specialized herbivores as their larvae feed on a single taxonomic group of plants (Miller et al., 2003). Therefore, specialist species of Lepidoptera at a low trophic level are more likely to be affected by reductions in phytodiversity than generalist predatory species of Neuroptera.

The dependence of the effect of diversity on the trophic level is in accordance with our third hypothesis that the determining parameter differs for different orders of insects. In contrast to the associations between the abundances of Neuroptera and Lepidoptera with microclimate, those of Diptera, Hemiptera, Psocoptera and overall insect abundance are positively associated with the vegetation in the shrub layer, as predicted by the second hypothesis. Overall insect and hemipteran abundances increased with increase in the species richness recorded in the shrub layer. This outcome is in line with other studies that reveal an increase in hemipteran abundance along a gradient in tree diversity (Sobek et al., 2009a) and an increase of general insect abundance with increase in phytodiversity (Schuldt et al., 2019). Although Sobek et al. (2009a) report positive effects of phytodiversity independent of the hemipteran trophic level (herbivores and predators), Schuldt et al. (2019) report that the direct effect and strength of the effect of phytodiversity vary between different functional groups (herbivores, predators and parasitoids) and between forest and grassland ecosystems.

Since there are several functional groups in Hymenoptera (herbivores, pollen feeders, parasitoids and predators) this study probably could not detect a general positive effect of phytodiversity on hymenopteran abundance. Furthermore, despite positive effects of phytodiversity on coleopteran abundance in temperate deciduous forests (Gering \& Crist, 2000; Sobek et al., 2009b) none of the associations were significant. As there are also several functional groups in Coleoptera (herbivores, predators and fungivores), this might account for the absence of an overall effect of phytodiversity. Other studies report high abundance of predatory beetles in mature forests with a high species richness of herbaceous plants (Zou et al., 2019), an increase in abundance of ground dwelling beetles with forest age (Lange 
et al., 2014), an increase in the abundance of dung beetles with increase in ambient temperature and fine sand content of the soil (von Hoermann et al., 2020) and a high abundance of saproxylic species occurring at different stages in the decay of wood (Buse et al., 2008).

Other associations with vegetation recorded in this study was the increase in the abundance of Diptera and Psocoptera associated with the cover of the shrub layer. Although Psocoptera are an important component of the arthropod community in forest canopies (Thornton, 1985; Halaj et al., 2000; Thunes et al., 2004), their diversity and abundance are rarely investigated in temperate forests (Kanervo $\&$ Kozlov, 2014). Species of both orders are herbivores, with dipteran larvae being leaf-miners and gall-inducers. The association with plant cover could simply be because it is quantitative measure of the resources available for insect herbivores. Generally, there is a positive correlation between plant cover and biomass in the understoreys of forests (Muukkonen et al., 2006). While no effect of plant biomass on insect abundance has been detected in grasslands (Borer et al., 2012) the abundance of Diptera in temperate deciduous forest is positively associated with the cover of tree and ground vegetation (Scherber et al., 2014; Fuller et al., 2018). Forests are more complex than grasslands in terms of biomass and structure of the plants in the different layers. While the diversity of ground vegetation may influence insect communities by direct bottom-up processes, difference in the canopy determine environmental conditions that may affect insect communities (Scherber et al., 2014). The importance of the shrub layer in affecting insect abundances recorded in this study is potentially based on the shrub layer being between the ground and canopy layer and influencing bottom-up processes and environmental conditions.

In contrast to the positive associations with vegetation described above, the abundance of Thysanoptera decreased with increase in the species richness of ground layer. Potentially, the window traps used in this study were not suitably positioned to capture mature individuals of species of Thysanoptera because they have tiny wings and are weak fliers. However, the temperatures favourable for the pest species of Thysanoptera are well known (Ganaha-Kikumura \& Kijima, 2016; e.g. Cao et al., 2018). According to the resource concentration hypothesis (Root, 1973), herbivory decreases with increase in phytodiversity, which would account for the pattern in the abundance of Thysanoptera recorded in this study.

Lastly, Diptera made up a high percentage $(59 \%)$ of catches of the window traps in this study. Individual window traps caught more than 200 Diptera most of which belonged to one morph species (visual inspection). This is probably linked to swarming behaviour, a feature of mature individuals of many species of Diptera. As part of their mating behaviour, males attract females by flying in swarms. The high number of Diptera caught by particular trap could indicate a swarm passed by that trap.

\section{Conclusions and limitations of the design of this study}

As Schuldt et al. (2019) suggest by investigating the associations between changes in the abundances of species and environmental conditions, this study provides insights into the factors that influence the abundance of flying insects in a temperate forest. However, there are some limitations due to design of this study. By using window traps, the focus was on flying insects and, therefore, only their individual numbers can be compared. Window trap catches may have a limited ability to reveal more detailed information on particular insect orders. For instance, one study reports the minimum number of moths caught per night as 10-12 individuals (Infusino et al., 2017), whereas in our study not more than three Lepidoptera were caught per trap over a period of three weeks. Different types of traps, such as, coloured pan traps for Diptera and Hymenoptera and UV-light traps for Lepidoptera need to be used in future studies comparing the absolute abundance of different groups of insects.

As there are seasonal changes in the vertical stratifications and abundances of insects in temperate forests (e.g. Gruppe et al., 2008; Goßner, 2008), varying the heights of traps and the periods sampled is likely to result in different numbers of insects being caught. For instance, the numbers of phloem/wood feeding beetles caught increase with trap height, whereas the opposite is the case for ambrosia beetles (Ulyshen \& Sheehan, 2019). Therefore, our results are incomplete because we did not sample insects in all the different layers in the forest, since traps were only installed in the lower canopy. In addition, the variation in mean temperature per day recorded in our study was only $17-18.6^{\circ} \mathrm{C}$, which in part accounts for its low explanatory power in terms of insect abundances.

The association between insect species richness and phytodiversity has been investigated by other studies (e.g. Siemann et al., 1998; Sobek et al., 2009b). Furthermore, Scherber et al. (2014) report that phytodiversity effects on higher trophic levels depend on the identity of species. Therefore, insect orders with diverse functional feeding groups (e.g. Coleoptera, Diptera, and Hymenoptera) need to be investigated in greater detail than in this study. However, insect abundance plays an important role in plantinsect-interactions concerning changes in biodiversity and associated ecosystem functions. Therefore, future investigations on insect diversity need to include insect abundance as it is important to combine it with species richness, because a species can be abundant (as observed in monocultures) and negatively affect biodiversity and functioning of ecosystems. Therefore, other aspects of biodiversity, such as number of families, species richness and insect biomass, need to be considered as they may reveal different results in terms of associations with phytodiversity.

Finally, the robustness of the BIC models used in this study is relatively low and statistical analyses of the results for the abundances of Psocoptera, Lepidoptera, Hymenoptera and Hemiptera also reveal suitable models without 
significant explanatory variables. Therefore, it can be assumed that either there was no effect, or other important factors affecting insect abundances were not measured (e.g. forest size, adjacent land use and age structure of the forest). In addition, the potential associations between insect abundance and phytodiversity, microclimate, stand structure and age can be altered by forest management. Consequently, forestry practices play an important role in determining the abundance of insects and conservation of insect diversity.

ACKNOWLEDGEMENTS. This paper was published with financial support of the Stiftung Universität Hildesheim. This field study was funded by Stiftung Universität Hildesheim. We specially thank the foresters who allowed us access to forest sites.

\section{REFERENCES}

Antvogel H. \& Bonn A. 2001: Environmental parameters and microspatial distribution of insects: a case study of carabids in an alluvial Forest. - Ecography 24: 470-482.

BARTOŃ K. 2016: MuMIn: Multi-Model Inference. URL: https:// CRAN.Rproject.org/package=MuMIn.

Bates D., Maechler M., Bolker B., Walker S., Christensen R.H.B., Singmann H., Dai B., Grothendieck G. \& Green P. 2017: Ime4: Linear Mixed-Effects Models using 'Eigen' and S4. URL: https://CRAN.Rproject.org/package $=1 m e 4$.

Berryman A.A. 1986: Population Dynamics of Forest Insects. Forest Insects: Principles and Practice of Population Management. Springer, New York, pp. 51-77.

BMEL 2016: Der Wald in Deutschland: Ausgewählte Ergebnisse der dritten Bundeswaldinventur. 56. Bundesministerium für Ernährung und Landwirtschaft, Berlin, 56 pp. [in German].

Borer E.T., Seabloom E.W. \& Tilman D. 2012: Plant diversity controls arthropod biomass and temporal stability. - Ecol. Lett. 15: 1457-1464.

Bouget C., Brin A. \& Brustel H. 2011: Exploring the "last biotic frontier": Are temperate forest canopies special for saproxylic beetles? - For. Ecol. Manag. 261: 211-220.

Buse J., Levanony T., Timm A., Dayan T. \& Assmann T. 2008: Saproxylic beetle assemblages of three managed oak woodlands in the Eastern Mediterranean. - Zool. Middle East 45: 55-66.

CaO Y., Li C., Yang W.-J., Meng Y.-L., Wang L.-J., Shang B.-Z. \& GAO Y.-L. 2018: Effects of temperature on the development and reproduction of Thrips hawaiiensis (Thysanoptera: Thripidae). - J. Econ. Entomol. 111: 755-760.

Cardinale B.J., Duffy J.E., Gonzalez A., Hooper D.U., Perrings C., Venail P., Narwani A., Mace G.M., Tilman D., Wardle D.A. ET AL. 2012: Biodiversity loss and its impact on humanity. - Nature 486: 59-67.

Chesson P. 2000: Mechanisms of maintenance of species diversity. - Annu. Rev. Ecol. Syst. 31: 343-366.

Chiarelli R.N., Pratt P.D., Silvers C.S., Blackwood J.S. \& Center T.D. 2011: Influence of hemperature, humidity, and plant terpenoid profile on life history characteristics of Boreioglycaspis melaleucae (Hemiptera: Psyllidae), a biological control agent of the invasive tree Melaleuca quinquenervia. Ann. Entomol. Soc. Am. 104: 488-497.

ERwiN T.L. 1982: Tropical forests: their richness in Coleoptera and other arthropod species. - Coleopt. Bull. 36: 74-75.

Floren A. \& Schmidl J. 2008: Canopy Arthropod Research in Europe: Basic and Applied Studies from the High Frontier. Bioform entomology, Nuremberg, 576 pp.
Fuller L., Fuentes-Montemayor E., Watts K., Macgregor N.A., Bitenc K. \& Park K.J. 2018: Local-scale attributes determine the suitability of woodland creation sites for Diptera. - J. Appl. Ecol. 55: 1173-1184.

Ganaha-Kikumura T. \& KiJima K. 2016: Effects of temperature on the development and fecundity of Thrips nigropilosus (Thysanoptera: Thripidae) on Chrysanthemum morifolium (Asterales: Asteraceae). - Appl. Entomol. Zool. 51: 623-629.

Gering J.C. \& CRIST T.O. 2000: Patterns of beetle (Coleoptera) diversity in crowns of representative tree species in an oldgrowth temperate deciduous forest. - Selbyana 21: 38-47.

Gossner M. 2008: Heteroptera (Insecta: Hemiptera) communities in tree crowns of beech, oak and spruce in managed forests: Diversity, seasonality, guild structure, and tree specificity. In Floren A. \& Schmidl J. (eds): Canopy Arthropod Research in Europe. Bioform entomology, Nuremberg, pp. 119-143.

Gruppe A. \& SoвeK S. 2011: Effect of tree species diversity on the neuropterid community in a deciduous forest. - Acta Entomol. Slov. 19: 17-28.

Gruppe A., Gossner M., Engel K. \& Simon U. 2008: Vertical and horizontal distribution of arthropods in temperate forests. In Floren A. \& Schmidl J. (eds): Canopy Arthropod Research in Europe. Bioform entomology, Nuremberg, pp. 383-405.

Halaj J., Ross D.W. \& MoldenKe A.R. 2000: Importance of habitat structure to the arthropod food-web in Douglas-fir canopies. - Oikos 90: 139-152.

Hallmann C.A., Sorg M., Jongejans E., Siepel H., Hofland N., Schwan H., Stenmans W., Müller A., Sumser H., Hörren T., ET AL. 2017: More than 75 percent decline over 27 years in total flying insect biomass in protected areas. - PLOS ONE 12: $\mathrm{e} 0185809,21 \mathrm{pp}$.

von Hoermann C., Weithmann S., Deissler M., Ayasse M. \& Steiger S. 2020: Forest habitat parameters influence abundance and diversity of cadaver-visiting dung beetles in Central Europe. - R. Soc. Open Sci. 7: 191722, 15 pp.

HolyoAK M., JAROSIK V. \& NovÁK I. 1997: Weather-induced changes in moth activity bias measurement of long-term population dynamics from light trap samples. - Entomol. Exp. Appl. 83: 329-335.

Hunter M.D. \& Price P.W. 1992: Playing chutes and ladders: heterogeneity and the relative roles of bottom-up and top-down forces in natural communities. - Ecology 73: 724-732.

Infusino M., Brehm G., Di Marco C. \& Scalercio S. 2017: Assessing the efficiency of UV LEDs as light sources for sampling the diversity of macro-moths (Lepidoptera). - Eur. J. Entomol. 114: 25-33.

Jonason D., Franzén M. \& Ranius T. 2014: Surveying moths using light traps: effects of weather and time of year. - PLOS ONE 9: e92453, 7 pp.

Kanervo J. \& Kozlov M.V. 2014: Diversity and abundance of arboreal psocids (Psocoptera) along latitudinal gradients in northern Europe. - Eur. J. Entomol. 111: 51-58.

Kass R.E. \& Raftery A.E. 1995: Bayes factors. - J. Am. Stat. Assoc. 90: 773-795.

Kelly C.K. \& Southwood T.R.E. 1999: Species richness and resource availability: A phylogenetic analysis of insects associated with trees. - Proc. Natl. Acad. Sci. USA 96: 8013-8016.

Lange M., Türke M., Pašalić E., Boch S., Hessenmöller D., Müller J., Prati D., Socher S.A., Fischer M., Weisser W.W., ET AL. 2014: Effects of forest management on ground-dwelling beetles (Coleoptera; Carabidae, Staphylinidae) in Central Europe are mainly mediated by changes in forest structure. For. Ecol. Manag. 329: 166-176. 
LEATHER S.R. 2018: "Ecological Armageddon" - more evidence for the drastic decline in insect numbers. - Ann. Appl. Biol. 172: $1-3$.

Levesque K.R., Fortin M. \& Mauffette Y. 2002: Temperature and food quality effects on growth, consumption and postingestive utilization efficiencies of the forest tent caterpillar Malacosoma disstria (Lepidoptera: Lasiocampidae). - Bull. Entomol. Res. 92: 127-136.

Logan J.A., Régnière J. \& Powell J.A. 2003: Assessing the impacts of global warming on forest pest dynamics. - Front. Ecol. Environ. 1: 130-137.

LoNDo G. 1976: The decimal scale for releves of permanent quadrats. - Vegetatio 33: 61-64.

McCann K.S. 2000: The diversity-stability debate. - Nature 405: 228-233.

McGeachie W.J. 1989: The effects of moonlight illuminance, temperature and wind speed on light-trap catches of moths. Bull. Entomol. Res. 79: 185-192.

Mech A.M., Tobin P.C., Teskey R.O., Rhea J.R. \& Gandhi K.J.K. 2018: Increases in summer temperatures decrease the survival of an invasive forest insect. - Biol. Invasions 20: 365-374.

Meineke E.K., Dunn R.R., Sexton J.O. \& Frank S.D. 2013: Urban warming drives insect pest abundance on street trees. PLOS ONE 8: e59687, 7 pp.

Miller J.C., Hammond P.C. \& Ross D.N.R. 2003: Distribution and functional roles of rare and uncommon moths (Lepidoptera: Noctuidae: Plusiinae) across a coniferous forest landscape. - Ann. Entomol. Soc. Am. 96: 847-855.

MuUKKonen P., MäKIPÄÄ R., Laiho R., MinkKinen K., VASAnder H. \& FiNÉR L. 2006: Relationship between biomass and percentage cover in understorey vegetation of boreal coniferous forests. - Silva Fenn. 40: 231-245.

Normann C., Tscharntke T. \& Scherber C. 2016: Interacting effects of forest stratum, edge and tree diversity on beetles. For. Ecol. Manag. 361: 421-431.

Novotny V. \& BAsset Y. 2005: Host specificity of insect herbivores in tropical forests. - Proc. Biol. Sci. 272: 1083-1090.

Pimm S.L. \& Raven P. 2000: Extinction by numbers. - Nature 403: 843-845.

PiotTo D. 2008: A meta-analysis comparing tree growth in monocultures and mixed plantations. - For. Ecol. Manag. 255: 781-786.

Rоот R.B. 1973: Organization of a plant-arthropod association in simple and diverse habitats: The fauna of collards (Brassica oleracea). - Ecol. Monogr. 43: 95-124.

Root H.T., Verschuyl J., Stokely T., Hammond P., Scherr M.A. \& BetTs M.G. 2017: Plant diversity enhances moth diversity in an intensive forest management experiment. - Ecol. Appl. 27: 134-142.

Rosenzweig M.L. 1995: Species Diversity in Space and Time. University Press, Cambridge, $436 \mathrm{pp}$.

Scherber C., Eisenhauer N., Weisser W.W., Schmid B., Voigt W., Fischer M., Schulze E.-D., Roscher C., Weigelt A., Allan E. ET AL. 2010: Bottom-up effects of plant diversity on multitrophic interactions in a biodiversity experiment. - Nature 468: 553-556.

Scherber C., Vockenhuber E.A., Stark A., Meyer H. \& TscharnTKE T. 2014: Effects of tree and herb biodiversity on Diptera, a hyperdiverse insect order. - Oecologia 174: 1387-1400.

Schuldt A., Ebeling A., Kunz M., StaAb M., Guimarães-Steinicke C., Bachmann D., Buchmann N., Durka W., Fichtner A., FORNOFF F. ET AL. 2019: Multiple plant diversity components drive consumer communities across ecosystems. - Nat. Commun. 10: 1-11.
Siemann E., Tilman D., Haarstad J. \& Ritchie M. 1998: Experimental tests of the dependence of arthropod diversity on plant diversity. - Am. Nat. 152: 738-750.

Simonet D.E., Clement S.L., Rubink W.L. \& Rings R.W. 1981: Temperature requirements for development and oviposition of Peridroma saucia (Lepidoptera: Noctuidae). - Can. Entomol. 113: 891-897.

SINGH J.S. 2002: The biodiversity crisis: a multifaceted review. Curr. Sci. 82: 638-647.

Sobek S., Gossner M.M., Scherber C., Steffan-Dewenter I. \& TscharntKe T. 2009a: Tree diversity drives abundance and spatiotemporal $\beta$-diversity of true bugs (Heteroptera). - Ecol. Entomol. 34: 772-782.

Sobek S., Steffan-Dewenter I., Scherber C. \& Tscharntke T. 2009b: Spatiotemporal changes of beetle communities across a tree diversity gradient. — Divers. Distrib. 15: 660-670.

Sobek S., Tscharntke T., Scherber C., Schiele S. \& SteffanDewenter I. 2009c: Canopy vs. understory: Does tree diversity affect bee and wasp communities and their natural enemies across forest strata? - For. Ecol. Manag. 258: 609-615.

STORK N.E. 1988: Insect diversity: facts, fiction and speculation. - Biol. J. Linn. Soc. 35: 321-337.

Strathdee A.T., Bale J.S., Block W.C., Coulson S.J., Hodkinson I.D. \& WebB N.R. 1993: Effects of temperature elevation on a field population of Acyrthosiphon svalbardicum (Hemiptera: Aphididae) on Spitsbergen. - Oecologia 96: 457-465.

TAUBer M.J. \& TAUBer C.A. 1983: Life history traits of Chrysopa carnea and Chrysopa rufilabris (Neuroptera: Chrysopidae): influence of humidity. - Ann. Entomol. Soc. Am. 76: 282-285.

THORNTON I.W.B. 1985: The geographical and ecological distribution of arboreal Psocoptera. - Annu. Rev. Entomol. 30: 175-196.

Thunes K., Skartveit J., GJerde I., Starý J., Solhøy T., FJellberg A., Kobro S., Nakahara S., zur Strassen R., Vierbergen G. et AL. 2004: The arthropod community of Scots pine (Pinus sylvestris L.) canopies in Norway. - Entomol. Fenn. 15: 65-90.

TiLMAN D. 1986: A consumer-resource approach to community structure. - Am. Zool. 26: 5-22.

ULYSHEN M.D. 2011: Arthropod vertical stratification in temperate deciduous forests: Implications for conservation-oriented management. — For. Ecol. Manag. 261: 1479-1489.

Ulyshen M.D. \& SheEHAN T.N. 2019: Trap height considerations for detecting two economically important forest beetle guilds in southeastern US forests. - J. Pest Sci. 92: 253-265.

VehviläInen H., Koricheva J. \& RUOHOMÄKI K. 2007: Tree species diversity influences herbivore abundance and damage: Meta-analysis of long-term forest experiments. - Oecologia 152: 287-298.

VoGel G. 2017: Where have all the insects gone? - Science 356: 576-579.

WhitTAKer J.B. \& TRIBE N.P. 1998: Predicting numbers of an insect (Neophilaenus lineatus: Homoptera) in a changing climate. - J. Anim. Ecol. 67: 987-991.

WiKTeLIUS S. 1981: Diurnal flight periodicities and temperature thresholds for flight for different migrant forms of Rhopalosiphum padi L. (Hom., Aphididae). - J. Appl. Entomol. 92: 449-457.

Yela J.L. \& Holyoak M. 1997: Effects of moonlight and meteorological factors on light and bait trap catches of noctuid moths (Lepidoptera: Noctuidae). - Environ. Entomol. 26: 1283-1290.

Zhang Y., Chen H.Y.H. \& Reich P.B. 2012: Forest productivity increases with evenness, species richness and trait variation: A global meta-analysis. - J. Ecol. 100: 742-749. 
Zou Y., Sang W., Bai F., Brennan E., Diekman M., Liu Y., Li L., Marples A., Shi H., Sui Z. et Al. 2019: Large-scale $\alpha$-diversity patterns in plants and ground beetles (Coleoptera: Carabidae) indicate a high biodiversity conservation value of China's restored temperate forest landscapes. - Divers. Distrib. 25: $1613-1624$.

Received April 28, 2020; revised and accepted September 25, 2020 Published online October 27, 2020

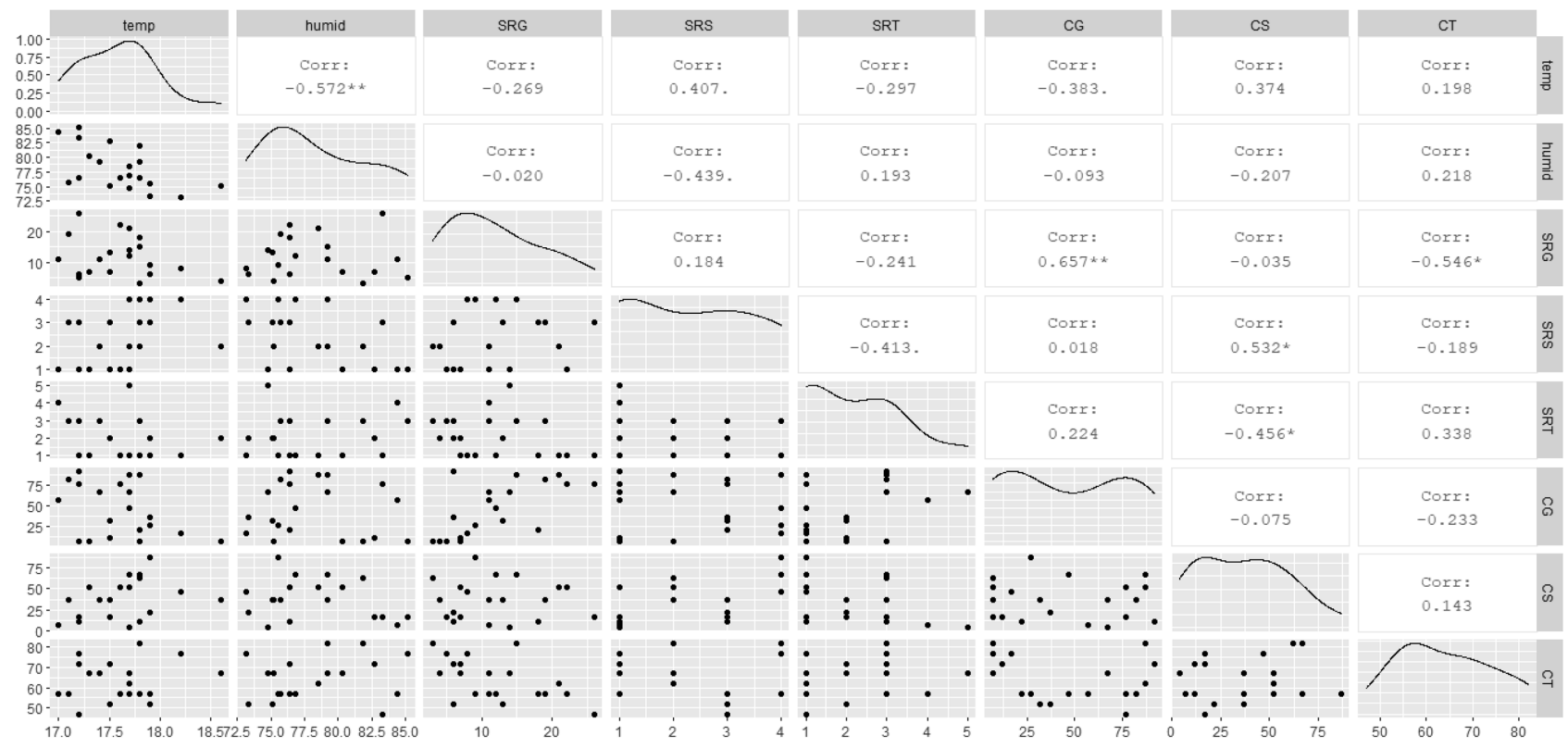

Fig. S1. Pairs plot for the explanatory variables. Values indicate the Pearson correlation coefficients. Abbreviations: temp - air temperature; humid - relative humidity; SRG - species richness recorded in the ground layer; SRS - species richness recorded in the shrub layer; SRT - species richness recorded in the tree layer; CG - cover of the ground layer; CS - cover of the shrub layer; CT - cover of the tree layer. 
Table S1. Selection of models for comparing ${ }^{1}$ the associations between abiotic conditions and vegetation and the abundance of insects and abundances of particular insect orders (individuals per window trap). Based on the Bayesian Information Criterion (BIC), models with similar strength of evidence, compared to the model with the lowest $\mathrm{BIC}(\triangle \mathrm{BIC}=0-2)$, are displayed. Linear regressions for models containing one explanatory variable are shaded grey.

\begin{tabular}{|c|c|c|c|c|c|c|c|c|c|c|c|c|c|c|}
\hline & $\#$ & Intercept & Temp & Humid & SRG & SRS & SRT & CS & CT & df & logLik & $\mathrm{BIC}$ & Delta & Weight \\
\hline \multirow{8}{*}{$\begin{array}{l}\text { Insect } \\
\text { abundance }\end{array}$} & 19 & 3.1669 & & & & 0.1842 & & & 0.0146 & 5 & -6.68 & 28.33 & 0.0000 & 0.0761 \\
\hline & 17 & 4.1600 & & & & 0.1610 & & & & 4 & -8.32 & 28.63 & 0.3000 & 0.0655 \\
\hline & 2 & 4.2383 & & & & & & 0.0079 & & 4 & -8.46 & 28.90 & 0.5753 & 0.0571 \\
\hline & 1 & 4.5303 & & & & & & & & 3 & -10.52 & 30.03 & 1.7020 & 0.0325 \\
\hline & 49 & 3.8759 & & & & 0.1991 & 0.0914 & & & 5 & -7.61 & 30.21 & 1.8787 & 0.0297 \\
\hline & 18 & 4.0966 & & & & 0.1084 & & 0.0050 & & 5 & -7.62 & 30.21 & 1.8849 & 0.0297 \\
\hline & 34 & 3.9321 & & & & & 0.1019 & 0.0102 & & 5 & -7.63 & 30.23 & 1.9050 & 0.0294 \\
\hline & 50 & 3.6592 & & & & 0.1400 & 0.1318 & 0.0072 & & 6 & -6.13 & 30.24 & 1.9082 & 0.0293 \\
\hline \multirow{15}{*}{$\begin{array}{l}\text { Coleopteran } \\
\text { abundance }\end{array}$} & 97 & 188.1764 & -9.9209 & & & & 1.7936 & & & 5 & -63.31 & 141.61 & 0.000 & 0.0488 \\
\hline & 77 & 62.8436 & -8.4591 & 1.3713 & -0.3154 & & & & & 6 & -61.98 & 141.94 & 0.336 & 0.0413 \\
\hline & 65 & 204.3434 & -10.6202 & & & & & & & 4 & -65.07 & 142.12 & 0.514 & 0.0377 \\
\hline & 37 & -91.3603 & & 1.3385 & & & 1.9102 & & & 5 & -63.62 & 142.23 & 0.621 & 0.0358 \\
\hline & 5 & -86.0403 & & 1.3230 & & & & & & 4 & -65.22 & 142.42 & 0.818 & 0.0324 \\
\hline & 68 & 186.1297 & -10.3103 & & & & & -0.1226 & 0.2694 & 6 & -62.28 & 142.53 & 0.919 & 0.0308 \\
\hline & 109 & 57.8414 & -7.8341 & 1.2546 & -0.2515 & & 1.0972 & & & 7 & -60.84 & 142.65 & 1.043 & 0.0290 \\
\hline & 73 & 248.9995 & -12.9896 & & -0.2483 & & & & & 5 & -63.87 & 142.72 & 1.110 & 0.0280 \\
\hline & 101 & 61.7470 & -6.5087 & 0.8513 & & & 1.7057 & & & 6 & -62.41 & 142.79 & 1.185 & 0.0270 \\
\hline & 113 & 214.2346 & -11.1775 & & & -1.5189 & 1.5882 & & & 6 & -62.42 & 142.81 & 1.204 & 0.0267 \\
\hline & 98 & 197.8201 & -10.3189 & & & & 1.5468 & -0.0568 & & 6 & -62.63 & 143.23 & 1.627 & 0.0216 \\
\hline & 105 & 222.8608 & -11.7272 & & -0.1731 & & 1.4061 & & & 6 & -62.65 & 143.27 & 1.661 & 0.0213 \\
\hline & 66 & 212.2347 & -10.9150 & & & & & -0.0728 & & 5 & -64.17 & 143.32 & 1.709 & 0.0208 \\
\hline & 69 & 68.1704 & -6.8732 & 0.8981 & & & & & & 5 & -64.20 & 143.37 & 1.766 & 0.0202 \\
\hline & 93 & 92.7363 & -9.4213 & 1.2348 & -0.2926 & -1.1122 & & & & 7 & -61.21 & 143.38 & 1.776 & 0.0201 \\
\hline \multirow{7}{*}{$\begin{array}{l}\text { Dipteran } \\
\text { abundance }\end{array}$} & 2 & 3.3745 & & & & & & 0.0142 & & 4 & -15.62 & 43.23 & 0.000 & 0.0791 \\
\hline & 34 & 2.8752 & & & & & 0.1661 & 0.0181 & & 5 & -14.53 & 44.04 & 0.803 & 0.0529 \\
\hline & 8 & 6.7759 & & -0.0585 & & & & 0.0110 & 0.0200 & 6 & -13.15 & 44.28 & 1.044 & 0.0469 \\
\hline & 38 & 6.7943 & & -0.0501 & & & 0.1856 & 0.0169 & & 6 & -13.22 & 44.41 & 1.177 & 0.0439 \\
\hline & 6 & 6.8674 & & -0.0440 & & & & 0.0128 & & 5 & -14.73 & 44.43 & 1.197 & 0.0435 \\
\hline & 72 & 19.8841 & -0.6046 & -0.0966 & & & & 0.0132 & 0.0269 & 7 & -11.78 & 44.52 & 1.291 & 0.0415 \\
\hline & 4 & 2.4617 & & & & & & 0.0133 & 0.0147 & 5 & -14.82 & 44.62 & 1.390 & 0.0395 \\
\hline \multirow{8}{*}{$\begin{array}{l}\text { Hemipteran } \\
\text { abundance }\end{array}$} & 2 & 4.2900 & & & & & & 0.0499 & & 4 & -45.07 & 102.13 & 0.000 & 0.0756 \\
\hline & 17 & 3.8348 & & & & 1.0023 & & & & 4 & -45.32 & 102.62 & 0.492 & 0.0591 \\
\hline & 10 & 5.1238 & & & -0.0806 & & & 0.0531 & & 5 & -44.24 & 103.46 & 1.330 & 0.0388 \\
\hline & 18 & 3.3442 & & & & 0.6387 & & 0.0358 & & 5 & -44.27 & 103.51 & 1.376 & 0.0380 \\
\hline & 25 & 4.6576 & & & -0.0914 & 1.1153 & & & & 5 & -44.36 & 103.70 & 1.569 & 0.0345 \\
\hline & 1 & 6.1400 & & & & & & & & 3 & -47.38 & 103.75 & 1.615 & 0.0337 \\
\hline & 6 & 21.8018 & & -0.2207 & & & & 0.0429 & & 5 & -44.40 & 103.78 & 1.644 & 0.0332 \\
\hline & 26 & 4.1675 & & & -0.0955 & 0.7382 & & 0.0379 & & 6 & -42.98 & 103.93 & 1.794 & 0.0308 \\
\hline \multirow{3}{*}{$\begin{array}{l}\text { Hymenopteran } \\
\text { abundance }\end{array}$} & 1 & 1.3818 & & & & & & & & 3 & -11.38 & 31.76 & 0.000 & 0.1272 \\
\hline & 17 & 1.1207 & & & & 0.1135 & & & & 4 & -10.53 & 33.05 & 1.291 & 0.0667 \\
\hline & 5 & 4.1831 & & -0.0358 & & & & & & 4 & -10.65 & 33.29 & 1.536 & 0.0590 \\
\hline \multirow{3}{*}{$\begin{array}{l}\text { Lepidopteran } \\
\text { abundance }\end{array}$} & 5 & 42.6899 & & -0.4910 & & & & & & 4 & -49.20 & 110.37 & 0.0000 & 0.1094 \\
\hline & 1 & 6.2875 & & & & & & & & 3 & -50.90 & 110.80 & 0.4213 & 0.0886 \\
\hline & 7 & 41.8450 & & -0.5421 & & & & & 0.0720 & 5 & -48.61 & 112.19 & 1.8171 & 0.0441 \\
\hline \multirow{7}{*}{$\begin{array}{l}\text { Neuropteran } \\
\text { abundance }\end{array}$} & 102 & -5.0821 & 0.6970 & -0.0987 & & & 0.2500 & 0.0084 & & 7 & -8.93 & 38.83 & 0.000 & 0.0836 \\
\hline & 5 & 9.5769 & & -0.1184 & & & & & & 4 & -13.61 & 39.19 & 0.366 & 0.0696 \\
\hline & 101 & -2.4431 & 0.6039 & -0.1060 & & & 0.1930 & & & 6 & -10.78 & 39.54 & 0.714 & 0.0585 \\
\hline & 13 & 9.4345 & & -0.1128 & -0.0251 & & & & & 5 & -12.39 & 39.76 & 0.934 & 0.0524 \\
\hline & 37 & 11.1309 & & -0.1424 & & & 0.1494 & & & 5 & -12.47 & 39.92 & 1.090 & 0.0485 \\
\hline & 7 & 9.7406 & & -0.1347 & & & & & 0.0172 & 5 & -12.56 & 40.09 & 1.262 & 0.0445 \\
\hline & 98 & -20.3876 & 1.1229 & & & & 0.2520 & 0.0107 & & 6 & -11.26 & 40.48 & 1.657 & 0.0365 \\
\hline \multirow{3}{*}{$\begin{array}{l}\text { Psocopteran } \\
\text { abundance }\end{array}$} & 1 & 8.0600 & & & & & & & & 3 & -53.36 & 115.70 & 0.0000 & 0.1272 \\
\hline & 2 & 5.6565 & & & & & & 0.0648 & & 4 & -52.19 & 116.36 & 0.6563 & 0.0916 \\
\hline & 65 & -30.1354 & 2.0284 & & & & & & & 4 & -52.63 & 117.24 & 1.5427 & 0.0588 \\
\hline \multirow{2}{*}{$\begin{array}{l}\text { Thysanopteran } \\
\text { abundance }\end{array}$} & 25 & 1.6244 & & & -0.0627 & 0.3301 & & & & 5 & -20.62 & 56.22 & 0.0000 & 0.1171 \\
\hline & 9 & 2.2550 & & & -0.0519 & & & & & 4 & -23.24 & 58.46 & 2.2456 & 0.0381 \\
\hline
\end{tabular}

${ }^{1}$ Models are ordered with those with the lowest BIC at the top (specified by rank). Positive and negative values for model variables indicate positive and negative associations with insect abundance, respectively. Temp - air temperature; Humid - relative humidity; SRG - species richness recorded in ground layer; SRS - species richness recorded in shrub layer; SRT - species richness recorded in tree layer; CS - cover of shrub layer; CT - cover of tree layer; logLik - log-likelihood; Delta - delta-BIC; Weight - Akaike weight. 